\title{
Current conditions in medical genetics practice
}

\author{
Deborah R. Maiese, MPA ${ }^{1}$, Alisha Keehn, MPA ${ }^{1}$, Megan Lyon, MPH ${ }^{1}{ }^{1}$, David Flannery, MD ${ }^{1}$ and \\ Michael Watson, MS, PhD ${ }^{1}$ Working Groups of the National Coordinating Center for Seven Regional \\ Genetics Service Collaboratives
}

Purpose: This study of current conditions in medical genetics practice is designed to inform public policy development and present possible solutions for improving access to genetic services.

Methods: Using the American College of Medical Genetics and Genomics Member Directory, membership directories from regional collaborative partners, listservs from national partners, and social media, a 16-question survey was electronically distributed in 2015.

Results: The responses of 924 genetics professionals and related providers present a snapshot of current practice and an assessment of workforce needs. More than $92 \%$ of the respondents (837/910) are involved in clinical care. Among geneticists, $60 \%$ spend more than $51 \%$ of their time in clinical care. Geneticists reported an average of 10.2 new patients per week and 7.8 follow-up visits per week. More than $62 \%$ of geneticists said that their practices were nearly full; $9.4 \%$ said that they were not taking new patients. The survey identified more than 100 geneticists and 200 genetic counselor job vacancies. Fewer than $18 \%$ of respondents reported use of telemedicine.

Conclusion: When compared with previously published workforce studies, these data show that wait times and average new patient caseloads have increased, while the number of geneticists has not.

Genetics in Medicine (2019) 21:1874-1877; https://doi.org/10.1038/s41436018-0417-6

Keywords: genetics workforce; access to care; wait times; telemedicine, National Coordinating Center for seven Regional Genetics Service Collaboratives

\section{INTRODUCTION}

"Will the U.S. have sufficient numbers of qualified health professionals to provide for the future genetic health care and service needs of the population?"1 That question opened a medical geneticist workforce report to the Health Resources and Services Administration (HRSA) of the US Department of Health and Human Services (HHS). Ten years later, the American College of Medical Genetics and Genomics (ACMG) as the National Coordinating Center (NCC) for the Regional Genetics Service Collaboratives (RCs) undertook a multipart needs assessment as part of a broader project supported by the Genetic Service Branch (GSB) in HRSA's Maternal and Child Health Bureau (MCHB). This report describes the 2015 findings on key genetic service practice components: wait times, average weekly patient visits, and the use of telemedicine. These data can inform federal agencies and others about the genetic services needs that a NCC/RC system might address to improve access ${ }^{2}$ in light of the dynamic changes in genomics and medicine (e.g., widespread adoption of recommended newborn screening, advances in genomic testing, reduced cost of DNA sequencing, and directto-consumer testing). ${ }^{3}$

\section{MATERIALS AND METHODS}

Membership directories (ACMG and other national professional organizations), as well as RC listservs and NCC social media, were used to reach genetic service professionals. The Genetic Provider Survey was disseminated electronically with the tag line "Shape the Future of Genetic Services." Separate data collectors were established for each listserv and were open for a four-week period on a rolling basis between September and December 2015.

The survey questions focused on three different areas: current conditions in your genetic practice, assessment of unmet needs, and recommendations for components of future regional genetic resource centers. The survey can be accessed at bit.ly/provider 15 .

This survey differs from the one administered a decade ago both in modality (electronic versus paper) and by respondents. The previous survey was mailed to 1500 ABMGG

\footnotetext{
${ }^{1}$ American College of Medical Genetics and Genomics, Bethesda, MD, USA. Correspondence: Deborah R. Maiese (dmaiese@acmg.net)
} 
diplomates and asked for responses whether or not members were involved in clinical care. ${ }^{4}$

\section{Statistical analysis}

Provider data were collected using an electronic survey platform, Survey Monkey, and imported into the IBM Statistical Package for Social Science (SPSS) for quantitative analysis. Descriptive statistics, such as frequencies and percentages, were calculated using the SPSS software.

\section{RESULTS}

A total of 924 genetics professionals participated in the survey: 249 medical geneticists (MD and $\mathrm{PhD}$ ), 536 genetic counselors, 30 metabolic dietitians, and 109 other genetic professionals (registered nurses [RNs], physician assistants [PAs], and laboratory specialists). Of the respondents, $37.5 \%$ worked in university hospitals, $19 \%$ in children's hospitals, $17 \%$ in community hospitals, $14.7 \%$ in clinics or private practice, and $11.8 \%$ in other settings (578/924). Genetic professionals responded from every region of the country. Most respondents $(72.3 \%, 589 / 815)$ reported that they were ten or more years from retirement. Among geneticists, $24.6 \%$ $(52 / 211)$ expected to retire in the next five years.

\section{Percent time in clinical care by discipline and setting}

More than $92 \%$ of the respondents (837/910) were involved in clinical care. Among geneticists, 60\% (149/248) spent more than $51 \%$ of their time in clinical care, $16.9 \%(42 / 248)$ provided care $26-50 \%$ of the time, and $16.1 \%(40 / 248)$ were involved in clinical care less than $25 \%$ of the time. Most genetic counselors $(73.9 \%, 393 / 532)$ reported spending more than half their time in clinical care. Geneticists $(n=$ 183) saw an average of 10.2 new patients per week and performed 7.8 follow-up visits per week. Across all disciplines, the average number of new patients seen per week was 8.9 $(n=725)$, and the number of follow-up visits averaged 5.3 $(n=696)$. Compared with a decade ago, geneticists' workloads have increased. In 2005, geneticists saw an average of six new patients per week and performed four follow-up visits. $^{1}$

When examined by practice setting, clinicians in university hospitals saw a weekly average of nine new patients and performed five follow-up visits. In children's hospitals, it was 7.4 new patients and 7.4 follow-up visits per week. In clinics, the weekly average was 10.6 new patients and 7.7 follow-up visits. Private or group practice clinicians reported the highest workload, with 12.2 new patients and 7.4 follow-up visits per week.

There were regional differences in the average weekly number of new (nonemergency) and follow-up visits, with providers in the Southeast reporting the highest workload: 11.9 new (nonemergency) visits and 8 follow-up visits. The lowest number of new (nonemergency) visits was 7.9, in Western States, and the lowest number of follow-up visits was 3.5, in New England.
Table 1 Typical waiting time for an nonemergency appointment for a new patient

\begin{tabular}{lcll}
$\begin{array}{l}\text { Typical waiting time for } \\
\text { an appointment for a } \\
\text { new patient }\end{array}$ & $\begin{array}{l}n=676 \\
(2003)\end{array}$ & $\begin{array}{l}\text { Geneticists } \\
n=210\end{array}$ & $\begin{array}{l}\text { All genetic } \\
\text { disciplines }\end{array}$ \\
\hline 1-2 work days & $4 \%$ & $<10$ & $11 \%$ \\
\hline 3-5 work days & $10 \%$ & $6 \%$ & $14 \%$ \\
$1-3$ weeks & $38 \%$ & $11 \%$ & $17 \%$ \\
$1-3$ months & $36 \%$ & $32 \%$ & $20 \%$ \\
\hline More than 3 months & $11 \%$ & $30 \%$ & $21 \%$ \\
\hline Not applicable or unsure & $2 \%$ & $20 \%$ & $17 \%$ \\
\hline
\end{tabular}

\section{New patient nonemergency appointment wait time}

Sixty-two percent of geneticists reported that their current wait time for a nonemergency new patient appointment was longer than one month (130/210). Across all respondents, those at children's hospitals reported the longest wait times for a new patient nonemergency appointment, with $39.4 \%$ $(43 / 109)$ estimating wait times to be more than three months; another $32.1 \%(35 / 109)$ said that the wait time was one to three months. In university hospitals, three-month wait times for a new patient nonemergency appointment were reported by $27.3 \%(59 / 216)$ of respondents and one-to-three-month wait times by $19.9 \%$ (43/216). This survey did not ask about emergency new patient appointments because during survey development genetics professionals' feedback indicated that emergencies were accommodated.

In comparing the 2015 and 2005 data, the findings demonstrate that new patient nonemergency appointment wait time has increased. In 2015, more than $30 \%$ of geneticists said that new patients wait more than three months for a nonemergency appointment $(63 / 210)$, while this was reported by only $10 \%$ of the survey respondents in 2005 (ref. ${ }^{4}$ ). Across all disciplines of respondents in 2015, 21\% reported that the wait time for a first appointment was longer than three months (168/812). (Table 1)

Both the 2005 and 2015 surveys asked questions about whether clinicians can or cannot accept new patients. Sixtytwo percent of geneticists (113/181) surveyed in 2015 said that practices were nearly full; $9 \%(17 / 181)$ said they were not taking new patients. Only 5\% of geneticists surveyed in 2005 reported full practices. ${ }^{4}$ In three regions (NYMAC, Mountain States and Western States), more than $12 \%$ of the respondents stated that their practice could not accept new patients. (Table 2)

\section{Telemedicine}

Few genetic professionals are using telemedicine; only $17.8 \%$ $(162 / 910)$ of respondents reported using telemedicine in their genetic practice. Genetic counselors were more likely to report telemedicine use $(20.8 \%, 111 / 533)$ than geneticists $(15.8 \%, 39 /$ 247). When examined by practice setting, genetic professionals in university hospitals $(22.7 \%, 49 / 216)$ reported only 
Table 2 Capacity to see new patients

\begin{tabular}{llll}
$\begin{array}{l}\text { Capacity to see new } \\
\text { patients }\end{array}$ & $\begin{array}{l}\text { All patient } \\
\text { care } \\
\text { geneticists } \\
n=376\end{array}$ & $\begin{array}{l}\text { Geneticists } \\
n=181 \\
(2015)\end{array}$ & $\begin{array}{l}\text { All genetic } \\
\text { disciplines } \\
n=712(2015)\end{array}$ \\
\hline $\begin{array}{l}\text { Cannot accept any more } \\
\text { genetics patients, } \\
\text { practice is full }\end{array}$ & $5 \%$ & $9 \%$ & $10 \%$ \\
$\begin{array}{l}\text { Can accept some new } \\
\text { genetics patients, } \\
\text { practice nearly full }\end{array}$ & $63 \%$ & $62 \%$ & $56 \%$ \\
$\begin{array}{l}\text { Can accept many new } \\
\text { genetics patients } \\
\text { practice far from full }\end{array}$ & $32 \%$ & $28 \%$ & $34 \%$ \\
\hline
\end{tabular}

slightly higher telemedicine use than those practicing in community hospitals $(20.3 \%, 29 / 143)$ and children's hospitals $(15.5 \%, 17 / 110)$.

\section{Genetics job vacancies}

Close to half of the respondents $(45.3 \%, 369 / 815)$ reported that their organization had geneticist job vacancies, $49 \%$ (399/ 815 ) did not have job vacancies, and 5.8\% (47/815) did not know whether there were vacancies. The respondents reported 100 open positions for medical geneticists and 200 genetic counselor positions at their institutions. Two regions (Heartland and Mountain States) had proportionately higher reports of job vacancies than the other five regions.

\section{Populations not receiving genetic services}

People in rural areas and on Native American reservations, non-English speakers, and uninsured individuals were identified as not accessing genetic services. Patients lost to follow-up and those with adult-onset genetic conditions were of concern. Barriers to accessing genetic services included distance to care, a lack of recognition among primary care providers about the need for a genetics referral, insufficient number of genetic providers, inadequate insurance coverage, and misconceptions about the nature of genetic services.

\section{Needed systems improvements}

An adequate genetics workforce that includes more geneticists, utilizes other types of providers in genetics, and provides increased autonomy for genetic counselors is needed. Respondents also noted the need for improved insurance coverage of appropriate tests and less burdensome preauthorization, unified medical records that identify genetic risks, evidence-based quality metrics for genetic services, cooperation between university centers that treat rare diseases, and expanded use of telemedicine.

Genetic providers were asked to rank order what resources would help them serve their patients in the coming decade. Of 14 response categories, technical assistance resources (e.g., insurance preauthorization, and setting up telegenetics) were ranked highest. Education on genetics and genetic consultations for nongenetic health-care providers and the development of standardized approaches to genetic services based on best practice and evidence-based guidelines were highly ranked.

\section{DISCUSSION}

While this survey did not ascertain the total number of currently practicing genetics professionals, the number of board-certified medical geneticists in 2015 was 1505 (refs. ${ }^{5,6}$ ). Following the Cooksey study design and the 2015 US Census numbers leads to a maximum estimate of 4.68 geneticists per 1 million population. ${ }^{7}$ It is imperative to note that the numbers above account for all clinical geneticists certified since 1982. Based on a 2007 ACMG member survey, a significant number are known to no longer be in practice and of those responding to the survey, only $45 \%$ of their time was spent in direct patient care (unpublished data). ${ }^{8}$ When taken in that context, there are at most just over 2 clinical geneticists per 1 million in the population. Job vacancies indicate that there are too few health-care professionals choosing or staying in the field of genetics. Until the training pipeline fills this void, staffing shortages ${ }^{9}$ in the clinical genetics system are likely to persist and to have a negative impact on patient access to genetic services.

To mitigate the effects of the workforce shortage, resources to improve the efficient practice of genetics are needed. Partnerships with clinicians in primary care and other settings are critical for ensuring appropriate referrals and timely diagnoses. Another strategy is for genetics professionals to work with public health systems to develop tools that help consumers navigate the complexities of the health-care systems and mechanisms that support the best use of clinicians' skill sets around genetics. Use of currently available technologies, such as clinical decision support tools in electronic health records and telemedicine, can also address some of these issues. An effort is underway to explore regional systems to address these issues. A future paper on this work is planned.

The provider survey results can also be considered in the context of a 2015 consumer survey done as part of the NCC needs assessment. When asked about barriers to accessing genetic counseling and/or genetic testing or to visiting a geneticist, a quarter of the consumers (26.5\%, 247/933) reported lack of providers with expertise in their particular genetic condition. Nearly half of adults with genetic disorders $(47 \%, 178 / 379)$ and more than one in ten children $(13 \%, 52 /$ 404) reported that it took more than five years from being initially symptomatic to receiving a diagnosis ${ }^{10}$ (Alexander et al. 2015). Consumer survey data reinforce the findings from this research, namely that there are delays in people getting the genetic services they need.

As with many surveys, getting clinician participation was a challenge. Owing to the multiple methods of collection (listservs, social media, member lists) and respondent types, a response rate is not readily calculable, which raises concerns about the generalizability of the data. Within the survey, there 
was variability in the item response. For example, only $62.5 \%$ (578/924) answered the next-to-last survey question about primary practice setting, which limits the ability to compare findings across workplace settings. However, as these data were discussed with NCC working groups, the consensus emerged that these data reflect their perceptions of current conditions in the genetics field.

\section{CONCLUSIONS}

New genetic discoveries are creating new opportunities in prevention, health maintenance, and the management of heritable disorders. To fully realize the potential of these medical breakthroughs and to ensure that all Americans have access to genetic services will take new practice models, ${ }^{10-12}$ new residency training models, and better reimbursement. Long-term investments are also needed to encourage students to join the genetics profession, so that ten years from now patients and families affected by genetic conditions are more quickly diagnosed and more easily able to access the primary, secondary, and tertiary care services they need. Genetics professional capacity within the health-care system will need to be substantially expanded and wait times for nonemergency appointments greatly reduced.

\section{ACKNOWLEDGEMENTS}

This project is supported by the Health Resources and Services Administration (HRSA) of the US Department of Health and Human Services (HHS) under Cooperative Agreement No. U22MC24100 (National Coordinating Center for the Regional Genetic Services Collaboratives). The NCC and the evaluation workgroup would like to thank Jill Shuger, the Project Officer at the HRSA/MCHB/GSB. This information or content and conclusions are those of the authors and should not be construed as the official position or policy of, nor should any endorsements be inferred by HRSA, HHS, or the US Government.

\section{DISCLOSURE}

The authors declare no conflicts of interest.

Publisher's note: Springer Nature remains neutral with regard to jurisdictional claims in published maps and institutional affiliations.

\section{REFERENCES}

1. Cooksey JA, Forte G, Benkendorft J, Blitzer MG. The state of the medical geneticsist workforce: Findings of the 2003 survey of American Board of Medical Genetics certified geneticists. Genet Med. 2005;7:439-443.

2. Kaye C. National Coordinating Center for the Regional Genetic Service Collaboratives. Regional genetic service models recommendation brief. 31 March 2016. http://www.nccrcg.org/docs/NCC/RSSM/NCC_RSSM_ Recommendation_Final_Brief.pdf.

3. Green ED, Guyer MS. Charting a course for genomic medicine from base pairs to bedside. Nature. 2011;470:204-213.

4. Cooksey JA, Forte G, Flanagan PA, et al. The medical genetics workforce: an analysis of clinical geneticist subgroups. Genet Med. 2006;8:603-614.

5. American Board of Medical Genetics and Genomics. Number of ABMGG certified specialists in medical genetics and genomics. January 2018. http://abmgg.org/pdf/Statistics\%20for\%20Webpage.pdf. Accessed 5 September 2018.

6. American Board of Medical Specialities. ABMS releases updated board certification report. 24 January 2017. https://www.abms.org/newsevents/abms-releases-updated-board-certification-report/. Accessed 5 September 2018.

7. US Census Bureau. American FactFinder. https://factfinder.census.gov/ faces/nav/jsf/pages/index.xhtml. Accessed 5 September 2018.

8. Benkendorf J. The medical genetics workforce: looking to the next five years. The ACMG Medical Geneticist: Quarterly Newsletter of the American College of Medical Genetics. 2010;5:8-12. http://www. acmg.net/PDFLibrary/Nolume-5-Number-3.pdf.

9. Hoskovec JM, Bennett RL, Carey ME, et al. Projecting the supply and demand for certified genetic counselors: a workforce study. J Genet Couns. 2018;1:16-20.

10. Feldman G. Presentation of the 2016 ACMG Foundation and March of Dimes Awards and Presidential Plenary Session: The Practice of Medical Genetics: Myths and Realities. The American College of Medical Genetics and Genetics Annual Clinical Genetics Meeting. March 9, 2016; Tampa, FL.

11. McPherson E, Zaleski C, Benishek K. Clinical genetics provider real-time workflow study. Genet Med. 2008;10:699-706.

12. American Academy of Pediatrics. The Future of Pediatric Education II (FOPE II) Project. 1999. https://www.aap.org/en-us/Pages/The-Future-ofPediatric-Education-II-Project.aspx. Accessed 2015.

Open Access This article is licensed under a Creative Commons Attribution-NonCommercial-ShareAlike 4.0 International License, which permits any non-commercial use, sharing, adaptation, distribution and reproduction in any medium or format, as long as you give appropriate credit to the original author(s) and the source, provide a link to the Creative Commons license, and indicate if changes were made. If you remix, transform, or build upon this article or a part thereof, you must distribute your contributions under the same license as the original. The images or other third party material in this article are included in the article's Creative Commons license, unless indicated otherwise in a credit line to the material. If material is not included in the article's Creative Commons license and your intended use is not permitted by statutory regulation or exceeds the permitted use, you will need to obtain permission directly from the copyright holder. To view a copy of this license, visit http://creativecommons.org/ licenses/by-nc-sa/4.0/

(C) The Author(s) 2019 